\title{
Sciendo
}

\section{Reasons, Contents and Experiences}

\author{
Daniel Laurier \\ Université de Montréal \\ Disputatio Vol. 1, No. 17 \\ November 2004
}

DOI: 10.2478/disp-2004-0009

ISSN: 0873-626X 


\title{
Reasons, contents and experiences
}

Daniel Laurier

Université de Montréal

\begin{abstract}
I propose what seems a plausible interpretation of the suggestion that the fact that someone has or lacks the capacity to make inferences of certain kinds should be taken as evidence that the contents of the states involved in these inferences are conceptual/nonconceptual. I then argue that there is no obvious way in which this line of thought could be exploited to help draw the line separating conceptual from nonconceptual contents. This will lead me to clarify in what sense perceptual experiences can be taken as providing reasons for beliefs.
\end{abstract}

\section{The dual role property}

I follow Peacocke 1992, and no doubt many others, in assuming that concepts are to be found (if at all) at the level of sense or mode of presentation, and to be identified with the constituents of contents (of a certain kind, namely, 'conceptual thoughts') ${ }^{1}$. Accordingly, I take it that an intentional content is wholly conceptual iff all its constituents are concepts, wholly nonconceptual iff none of its constituents are concepts $^{2}$, and partially conceptual (nonconceptual) iff it is neither wholly conceptual nor wholly nonconceptual. It is worth pointing out that on

\footnotetext{
${ }^{1}$ According to another usage, especially popular among cognitive psychologists, concepts are taken as mental symbols, and hence as bearers of content. But this is a largely terminological matter which need not concern us here.

2 In this perspective, a mental state or attitude can be said to be conceptual (nonconceptual) only insofar as its content is conceptual (nonconceptual). Hence, the distinction between the conceptual and the nonconceptual is here taken as pertaining primarily to intentional contents, and only derivatively to states or attitudes.
}

Disputatio, Vol. I, No. 17, November 2004 
this construal, nonconceptual contents will have to have 'nonconceptual modes of presentation' as their constituents ${ }^{3}$.

It is widely admitted that there should be a close connection between conceptual articulation and inferential articulation, and/or between concept possession and inferential capacities, which suggests that the fact that someone has or lacks the capacity to make (correct) inferences of certain kinds should be taken as evidence that the contents of the states involved in these inferences are conceptual/nonconceptual, and hence that these states themselves are conceptual/nonconceptual.

In this section, I will explain one way in which this suggestion could be pursued. It will turn out that both McDowell and Crane invoke this kind of idea in order to sustain the opposite conclusions that perceptual experiences are conceptual, and that they are nonconceptual, respectively. In the next section, I will argue that there is no obvious way in which this line of thought could be exploited to help draw the line separating conceptual from nonconceptual contents; and in the last, I will raise a difficulty with Crane and McDowell's common assumption that perceptual experiences can provide reasons for beliefs, which will lead me to clarify in what sense it should be taken. But I must first say a few words about how I think about inferences.

As I use these notions, there is an intuitive distinction between inferences, on the one hand, and entailment or consequence relations on the other. The contrast I have in mind is intuitively this: entailment relations may either obtain or not obtain between any contents, or representations ${ }^{4}$, while inferences are (at least) transitions between (contentful) states or attitudes, which may be evaluated as correct or incorrect. In other words, it may be true or false that this entails that (and correct or incorrect to say or think that this entails that, or to infer that from this), but it is neither correct nor incorrect for this to entail that (which I think is in full agreement with ordinary usage).

It is of course no easy task to say exactly what an inference is supposed to be, especially if one intends to cover all kinds of reasoning and not only 'theoretical' reasoning; but it is worth trying to be

\footnotetext{
${ }^{3}$ These assumptions are explained, discussed and defended in another paper to appear in Grazer Philosophische Studien.

${ }^{4}$ There could also be entailment relations between mental states or attitudes, but only in the sense that the fact that one believes p may or may not entail the fact that one believes $\mathrm{q}$ (and this may be the case no matter what the relation is between $\mathrm{p}$ and $\mathrm{q})$.
} 
more explicit about what is or might be involved in inferential competence, since this could help us to reach a better understanding of what concepts are supposed to be. As I use this term, an inference is 'theoretical' when it involves only thetic states or attitudes, i.e., states or attitudes which have the mind-to-world direction of fit (the most prominent of which are beliefs). But even though such inferences involve only thetic states or attitudes, it would be misleading to say that these states or attitudes themselves are to be regarded as playing the roles of premises and conclusion. When my beliefs that $p$ and that $p$ entails $q$ lead me to believe that $q$, I am not inferring that I believe that $\mathrm{q}$ from the fact that I believe that $\mathrm{p}$ and that $\mathrm{p}$ entails $\mathrm{q}$; rather, I am inferring that $q$ from the fact that $p$ and that $p$ entails $q$. My beliefs provide the premises and conclusion of the inference, but are not to be identified with these ${ }^{5}$. And this is so even though my inferring the conclusion from the premises involves my 'going' from the premiseproviding states to the conclusion-providing state. Note also that even when the premises of such an inference can be described as the reasons for which I believe that $\mathrm{q}$, it is seldom appropriate to describe them as the reasons for which q: although premises can sometimes be described as reasons, they are most often not reasons for the conclusion, but reasons for believing the conclusion (for concluding that q).

For all that has been said so far, there is nothing to distinguish concepts from what might be called 'nonconceptual partial senses ${ }^{6}$ : both are constituents of the contents of mental states/attitudes, and both are apt to induce entailment relations. But for all we know, it might be possible to find some distinguishing features along the following lines: if $\mathrm{X}$ has (lacks) the capacity to make certain kinds of inferences involving a certain contentful state, then the content of this state is (wholly or partially) conceptual (nonconceptual), or more generally: if $\mathrm{X}$ has (lacks) the capacity to make certain kinds of inferences, then $\mathrm{X}$ has (lacks) the capacity to be in conceptually contentful states. But what kinds of inferences might be relevant here, and how could they ever be characterized in non-question-begging terms (i.e., in terms which do not presuppose that the states involved in these inferences are either conceptual or nonconceptual)? belief.

${ }^{5}$ Unless the word 'belief' is used, as it sometimes is, to designate the content of a

${ }^{6}$ I use this phrase to designate these constituents of contents which are not concepts. Accordingly, 'concepts' is just another word for 'conceptual partial senses.' 
The intuition behind this line of thought might be something like this. It would seem that if someone has the capacity to be in conceptual states, then his/her inferential repertoire must include all inferences linking any of these states to any other, irrespective of any entailment relation which may or may not obtain between them. This implies that if someone has the capacity to be in a certain conceptual state, then his/her inferential repertoire includes both inferences in which this state is premise-providing and inferences in which it is conclusion-providing. One could perhaps even go further and claim that possessing this property, which I call the 'dual role' property, is not only necessary, but also sufficient for a state to be conceptual: if someone's inferential repertoire includes both inferences in which a certain state is premise-providing and inferences in which it is conclusion-providing, then this state is conceptual.

Obviously, such a course will appeal to anyone who is already inclined to think that experiences, in particular, are nonconceptual. For since it is widely acknowledged that experiences cannot play the conclusion-providing role in any inference ${ }^{7}$, it could at once be concluded that experiences are nonconceptual ${ }^{8}$. But even then, for this course to have any chance of succeeding, or more accurately, for it to be true that experiences do not possess the dual role property, an inference should be taken to involve more than a merely causal relation between contentful states.

For there is nothing to prevent an experience from being caused by any kind of contentful state whatsoever, and on such a weak understanding of inferences, experiences would thus have to be counted as conclusion-providing. It would not help to pretend that when, e.g., a belief causes an experience, we are dealing with an inference in good standing, but it is only that all such inferences (where the conclusionproviding state is an experience) are incorrect. For there is nothing to prevent a belief, the content of which entails that $q$, to cause an experience that q; and it is hard to see why such an inference, if it really is an inference, could be described as incorrect.

\footnotetext{
${ }^{7}$ This is the nearly uncontroversial half of what is often expressed by saying that experiences are inferentially basic: they cannot be inferred from anything, but one could arguably infer from them. By contrast, actions (as well, perhaps, as all telic attitudes) could be described as inferentially terminal, or ultimate: they can arguably be inferred from something else, but nothing can be inferred from them.

${ }^{8}$ Notice that there is no need to take possession of the dual role property as sufficient for being conceptual in order to be entitled to this conclusion.
} 
The trouble with such causal transitions has nothing to do with the entailment relations that may or may not obtain between the relevant contents. But it may have to do with the fact that we are not supposed to have any direct voluntary control on what we are experiencing at any given moment, i.e. with the fact that experiences are essentially 'passive.' One potential source of difficulty for this view comes from the fact that many people will claim that we do not have any direct voluntary control over what we believe either ${ }^{9}$. So if this lack of control is the reason why experiences are not conclusion-providing, then beliefs (or at least some of them), on such a view, should also fail to be conclusion-providing and thus should not count as conceptual. One would not necessarily have to worry about this, since nothing forces one to maintain that all beliefs are conceptual ${ }^{10}$. But in any case, it is possible to improve on this diagnosis by appealing to the suggestion made above, that the premises of a correct inference can be described as reasons for being in the conclusion-providing state. Whether beliefs are subject to voluntary control or not, we often have reasons for believing what we believe, but we can (and need) have no reason for experiencing what we experience, and (it may be suggested) this is why experiences are not conclusion-providing and do not have the dual role property. To say this is to embrace the view that an essential feature of any inference is that the contents of the premise-providing states are apt to be reasons for being in the conclusionproviding state ${ }^{11}$.

If experiences lack the dual role property because they cannot be conclusion-providing, it may now be asked, are there contentful states which lack this property because they cannot be premise-providing?

There might be some temptation to mention actions as a case in point here, in view of the fact that they could be seen as having a role in reasoning, which would be complementary to that of experiences. But this would be irrelevant, since we are restricting ourselves to contentful states or attitudes and (even ignoring the fact that actions

\footnotetext{
${ }^{9}$ Indeed, one standard objection to doxastic voluntarism is that beliefs based on perception are involuntary. See, e.g., Alston (1989, 91-92).

${ }^{10}$ On the other hand, one would then have to explain why a belief could not be both conceptual and irresistible.

${ }^{11}$ As will soon become evident, this is meant to hold only of thetic premiseproviding states/attitudes. Since such states/attitudes do play a role in both theoretical and practical inferences, the claim must not be understood as being restricted to theoretical inference.
} 
are not states) it is doubtful that ordinary actions are contentful. Yet actions are disturbing, in that we certainly often have reasons for doing what we do. By this standard, it would seem natural to grant that actions can play a conclusion-providing role in inference, if only they 'provided' anything. My way of doing justice to this intuition is to admit that not all inferences need have a conclusion, or more accurately, that not all inferences need be concluded by something which introduces a conclusion. It is obvious that I can conclude a piece of reasoning by believing, or judging, or desiring that $\mathrm{p}$. But this is to do something, and if we are prepared to allow that such contentful doings can conclude a piece of reasoning, perhaps there is no obstacle to granting that other kinds of doings can also count as concludings (even when they are not contentful). This may superficially look like a 'degenerate' case, but there is every reason to think that it is just the opposite: it is likely that such practical inferences (where the 'concluding' is not contentful) are the most basic or primitive kind of inference.

There are admittedly other kinds of practical inferences, where the concluding state/attitude is, e.g., a desire, an intention, or some other telic $^{12}$ state/attitude. The question is whether such telic states/attitudes can play a premise-providing role, and thus possess the dual role property.

One may be tempted to deny that they can, on the ground that the contents of such states/attitudes never count as reasons for being in any contentful state/attitude whatsoever. On this view, a premise must be a reason (though not, as I have already said, a reason for the conclusion) and only thetic states introduce reasons. There obviously is something to be said for this view, since, intuitively, when I desire that $p$, that $p$ is not thereby a reason for me to do, want, or believe anything. But if we are going to deny, on this ground, that telic states/attitudes can play a premise-providing role, then we should also deny that they can play a conclusion-providing role. For it seems just as odd to call the content of my desire 'a conclusion,' when I am led to this desire by some piece of reasoning.

The trouble, I suggest, is that 'premise' and 'conclusion' have misleading connotations, when used outside the sphere of theoretical reasoning (or more exactly, when applied to anything else than the

\footnotetext{
${ }^{12}$ I borrow this term from Humberstone 1992. It applies to states or attitudes which have the world-to-mind direction of fit.
} 
contents of thetic states/attitudes). Consider someone who desires that $\mathrm{p}$, believes that if $\mathrm{q}$ then $\mathrm{p}$, and is thereby led to desire that $\mathrm{q}$. As we have been using these terms so far, the desire that $p$ here plays a premise-providing role and the desire that $\mathrm{q}$ a conclusion-providing role. Yet 'that p' can hardly be described as having here the force of a reason for the agent to desire that q. If there is anything here which can be described as a reason for desiring that $\mathrm{q}$, it is that if $\mathrm{q}$ then $\mathrm{p}$. Furthermore, it is hard to see why 'that q' should be described as a conclusion, given that the entailment or evidential relation between the contents involved does not go from 'p' and 'if q then p' to 'q,' but rather from ' $q$ ' and 'if $q$ then $p$ ' to 'p.' In other words, it is the content of the conclusion-providing state which supports the content of a premise-providing state; and this of course clashes with calling the first content 'a conclusion' and the second 'a premise' ${ }^{\text {'13 }}$.

However, denying that telic states/attitudes (or their contents) can play a significant role in reasoning is not a good way to avoid having to grant that the content of a conclusion-providing state may not be a 'conclusion' and the content of a premise-providing state may not be a premise, since it seems obvious that desiring or intending something may lead one to desire, intend or do something else, and that the contents of these desires and intentions do contribute to determine whether such a move is correct or incorrect ${ }^{14}$. A purely terminological repair seems in order here, so I propose that we use the phrases 'consequent state/attitude' and 'antecedent state/attitude' instead of 'conclusion-providing state/attitude' and 'premise-providing state/attitude,' respectively. The suggestion made above, that an essential feature of any inference is that the contents of the premiseproviding states/attitudes are apt to be reasons for being in the conclusion-providing state/attitude, should accordingly be revised along the following lines: an essential feature of any inference is that the contents of its thetic antecedent states/attitudes are apt to be reasons for being in the consequent state/attitude.

\footnotetext{
${ }^{13}$ The foregoing remarks have been much influenced by Stampe's 1987 (especially section VII) insightful analysis of practical reasoning.

${ }^{14}$ In other words, just as a theoretical inference is correct only if there is some appropriate relation between the contents of the thetic states involved, such a practical inference will be correct only if there is some appropriate relation between the contents of the telic states involved (and eventually,between them and the contents of other kinds of states). It is only that the relations in question need not be the same in both cases.
} 
In any case, it should be clear that if we were to deny that telic states play a role in reasoning, this would mean that they all lack the dual role property, and hence, that they are all nonconceptual, which is certainly false. But on the other hand, to admit that they can all be involved both as antecedent and as consequent states/attitudes would mean that no telic state/attitude is nonconceptual, which is very unlikely, if there are to be nonconceptual states/attitudes at all.

What is needed is some reason to believe that telic states, just as thetic states, divide into those which can and those which cannot play both the role of antecedent state and the role of consequent state. Experiences were found to lack the dual role property in virtue of the fact that they cannot play the consequent-state role; we then started looking for states/attitudes which would lack it in virtue of not being able to play the role of antecedent state, and turned to telic states in order to see if they met this condition. But this was a mistake. For on reflection, it is likely that for every agent, some of the telic states in which he/she can be will share the feature which was found to be characteristic of experiences: they will not be able to play the consequent-state role. These would be like 'intrinsic' desires, in that they could (no doubt with a little help from their friends) lead to further telic states, but could not themselves result from any inference. It should have been clear that when we were discussing experiences above, it was perceptual experiences (or perhaps more generally, states of 'experiential receptivity') that we primarily had in mind, since we thought of them as providing reasons. But it may now be acknowledged that experiences can be either of the thetic (perceptual) or the telic (conative) variety, and that both kinds of experiences are united by the fact that they are inferentially basic and lack the dual role property for this same reason (i.e., for the reason that they cannot fill the consequent-state role).

However that may be, the upshot of this discussion is that no contentful state/attitude seems to lack the capacity to play the role of antecedent state/attitude, and that the claim according to which a state/attitude is (wholly) conceptual only if it possesses the dual role property actually boils down to the claim that it is (wholly) conceptual only if it possesses the consequent-state role property. This is so whether or not we accept that there might be telic experiences. But, though I do accept this, it should be emphasized that insofar as it seems highly plausible that one can be in a telic state with a given content iff one can be in a thetic state with the same content (or in 
other, but less careful words, that one must be able to desire everything that one can believe, and be able to believe everything that one can desire), there is every reason to think that it should be possible to characterize the contrast between conceptual and nonconceptual states while remaining completely within the sphere of thetic states/attitudes.

\section{Conceptual contentfulness and inference}

The condition that a state/attitude is (wholly) conceptual only if it possesses the dual role property thus delivers the result that perceptual experiences are nonconceptual ${ }^{15}$. This will certainly be welcomed by those who believe in nonconceptual content. But it should be observed that no reason has yet been given as to why failing to possess the dual role property should be taken as evidence that the states/attitudes in question are (wholly or partially) nonconceptual!

The question is made especially relevant by the fact that while Crane (1992, 151-153) relies on the fact that experiences lack the capacity to fill the consequent-state role to argue that they are non-

\footnotetext{
${ }^{15}$ More accurately, the fact that perceptual experiences lack the dual role property licences at most the conclusion that they are either wholly or partially nonconceptual. In other words, possessing the dual role property could at best be taken as a (necessary, sufficient, or necessary and sufficient) condition for being wholly conceptual; it could therefore only yield a (sufficient, necessary, or sufficient and necessary) condition for being either wholly or partially nonconceptual. In other words, the dual role condition could not help to distinguish between wholly and partially nonconceptual states or contents. A further criterion would be needed to separate them, unless it can be shown that there can be no partially nonconceptual states or contents. But this is unlikely, since it is unlikely that there are wholly nonconceptual states unless some of them can play some role in some piece of reasoning, and there could not be such wholly nonconceptual states unless there are also some partially nonconceptual ones. For suppose that some wholly nonconceptual state A provides a reason to be in some wholly conceptual state B. It must at least be possible that someone realizes that this is so; but one could hardly realize this without being (or having the capacity to be) in some mixed (partially conceptual and partially nonconceptual) state. Any such mixed state will either lack or possess the dual role property. If it possesses it, then this will show that possessing this property is not sufficient for being wholly conceptual, and if it does not possess it, this will show that lacking this property is not sufficient for being wholly nonconceptual. It will fall either on the side of wholly conceptual states or on the side of wholly nonconceptual states. In either case, a further criterion will be needed.
} 
conceptual $^{16}$, McDowell (1994, 162-166) relies (in part) on the fact that they can fill the antecedent-state role to argue for the opposite conclusion that they are (indeed, must be) conceptual. This strongly suggests that McDowell rejects the view that possessing the dual role property is a necessary condition for being conceptual. One could then be led to suppose either that McDowell takes it as a sufficient condition that a state/attitude can fill either the premise-providing or the conclusion-providing role, or that he takes it as necessary and sufficient that a state/attitude can fill the premise-providing role. It does not matter which way we go since as we have seen there are no contentful states/attitudes which have the capacity to play the consequent-state role while lacking the capacity to play the antecedentstate role.

What has to be assessed is whether the fact that experiences have the capacity to play the antecedent-state role, but lack the capacity to play the consequent-state role, gives anyone any ground for concluding either that they must be conceptually contentful or that they must be nonconceptually contentful.

Let us start by reviewing McDowell's argument to the conclusion that experiences must be conceptually contentful, if they are to provide reasons for beliefs ${ }^{17}$. The argument is indirect, and occurs on pp 162-166 of his 1994, in the course of a criticism of Peacocke's (1992, 66 and 80) view that the nonconceptual content of an experience can provide a good reason for forming a belief, such as the belief that some demonstratively presented object falls under some observational concept. On Peacocke's view this means that there are 'rational linkages' between the nonconceptual and the conceptual states/attitudes.

McDowell $(1994,162)$ acknowledges that:

16 'While they [perceptions] may be pieces of evidence, they are not revisable on the basis of other evidence - whether that evidence is another belief or another perception. Moreover, if conceptual structure is only imposed by these evidential relations and the other inferential relations, then perceptions will not have conceptual structure. This is why their contents will not have inferentially relevant constituents: they will not be composed of concepts.' (Crane 1992, 151-152)

${ }^{17}$ Given that McDowell recently $(2002,293)$ confessed that he does not offer an argument for the claim that only what is conceptually shaped can justify, and that this is a claim which 'stands on its own feet,' the considerations I am going to mention may not exactly have been meant as an 'argument.' But in any case, they do bear on the issue. 
it seems a routine thought that there can be rational connections between the world's being as a possessor of one bit of content represents it and the world's being as a possessor of another bit of content represents it, independently of what kind of content is in question,

but contends that this is not enough to establish what, according to him, needs to be established, namely, that the nonconceptual content of an experience can constitute someone's reason for believing something. He goes on to suggest that someone could indeed argue to the conclusion that something is $\mathrm{F}$ from the premise that he/she is having an experience with a certain nonconceptual content, and contends that this would provide a case where someone forms a belief 'for a reason supplied by an experience, with its nonconceptual content' (1994, 164). But, he points out, this would require the person in question to possess the concept of nonconceptual content, and thus prevent experiences from providing reasons for belief to ordinary people. Furthermore:

If we restrict the role of experience in empirical thought to its being something from which we can argue to a conclusion about the world, given that we know the relevant theory, then we cannot conceive experience as itself constituting access to the world. $(1994,165)$

He then complains that a view such as Peacocke's forces one to sever the 'time-honoured' connection between the reasons for which one thinks what one thinks, and the reasons one can give for thinking it. Since the reasons one can give, 'in so far as they are articulable' (1994, 165), must be conceptual, it follows, by the 'time-honoured connection,' that one's reasons for thinking what one thinks must also be conceptual ('in so far as they are articulable').

There are a number of things to be said in response to these remarks of McDowell's. But before I proceed, it must be emphasized that I do not mean to suggest that they exhaust McDowell's motives for being suspicious about the idea of nonconceptual content. I am only trying to isolate one interesting line of argument, and in order to do that I must clear the way by discarding some of what McDowell seems to be saying as misguided.

I think, in particular, that McDowell is wrong in claiming to have described a case where one's reason for believing something is 'supplied by an experience, with its nonconceptual content,' though the 
relevant experience only counts as a reason in virtue of the fact that the subject knows a theory connecting nonconceptual experiences to beliefs. I agree that if this were indeed the case, then it would not have been shown that experience itself constitutes access to the world, but it seems a mistake to suggest that in a case such as the one offered by McDowell, the experience itself, or its content, can aptly be described as one of the subject's reasons for believing anything. As McDowell himself describes the case, the subject's 'premise' is supposed to be that he/she enjoys an experience with a certain nonconceptual content, and though such a 'premise' is about some experience and its content, it does not in any way give the content of the relevant experience $^{18}$. McDowell may have described a case where the subject has indeed a reason for believing as he believes, but not one where his/her reason is supplied by experience.

I also have some misgivings about McDowell's use of the qualifying phrase 'in so far as they are articulable.' If a reason must be conceptual 'in so far as it is articulable,' does it mean that it may be nonconceptual in so far as it is not articulable? It is doubtful that this is what McDowell has in mind here. It may be tempting to suppose that a reason counts as 'articulable' as soon as, and in virtue of the fact that, it can be verbally expressed. But if we take it in this way, and assume that to give a reason is to verbalize it, then his remark comes down to the idea that one can only have conceptual reasons, because one can only have reasons that one can give ('the time-honoured connection'), and one can only give conceptual reasons (i.e., the 'in so far as they are articulable' part becomes redundant). Moreover, since everything that can be the content of a mental state/attitude can probably be a reason for something, what McDowell calls the 'time-honoured connection' between reason and discourse looks suspiciously like the very controversial thesis that all forms of intentionality depend on language; and to that extent, it seems to beg the question against nonconceptual contents. There remains the possibility that to be 'articulable' is something like to have some relevant logical or inferential structure. But there is nothing to be expected from such a reading, since it has already been seen that logical or inferential articulation does not require conceptual articulation.

\footnotetext{
${ }^{18}$ It could perhaps be taken as giving the content of some higher-order experience, but I assume this is not how McDowell intends it to be taken.
} 
As was pointed out above, McDowell is ready to acknowledge what he calls 'the routine thought' that there can be 'rational connections' between the contents of any two intentional states/attitudes. I take it that in this context, to talk of 'rational connections' is just another way of making reference to what I earlier called 'entailment' relations among intentional contents. His main contention seems to be that the fact that there are such connections is not sufficient to ensure that an intentional content is always apt for being someone's reason for believing something. Further conditions must be satisfied, besides entertaining 'rational connections' with other contents (though in the end, McDowell wants to hold that all genuine intentional contents must also satisfy these further conditions, whatever they are). It is notoriously unclear, however, what these further conditions could amount to.

McDowell's view seems to be that although there are (or might be) 'rational connections' linking nonconceptual contents to conceptual contents, only the latter can be someone's reasons for being in any contentful state or for doing anything. But I fail to see that the notion of 'a reason' requires or even sustains any such view, and no argument that it does has been proposed. In particular, no argument seems to be forthcoming from McDowell's idea that the 'space of reasons' is not constrained by anything outside itself (i.e., that it is 'unbounded'). For this idea does not require that the space of reasons be equated with the space of concepts, and seems perfectly compatible with the claim that it coincides instead with the (larger) space of intentional contents.

Moreover, McDowell's position seems to rest on a dubious conception of reasons (one which takes them to be more finely individuated than truth-conditions). Notice that it does seem natural to hold that when I say that my reason for doing something is, e.g., that $x$ is $F$, what I thereby take as my reason is the fact that $x$ is $F$, and not the way it presents itself to me (e.g., not the fact that I think of this fact as the fact that $x$ is $F$ ). For one would normally want one's action towards an object to depend on the properties of this object and not on the way in which one conceives of these properties, which is not to deny that the fact that some property presents itself in a certain way may explain why (and perhaps even be a reason for which) one takes the fact that something has this property as one's reason to act in a certain way. Suppose I recognize that the very same property is presented to me in two different ways, now as 'being F' and now as 'being G,' and that I take the fact that $\mathrm{x}$ is $\mathrm{F}$ as my reason for doing something, would 
not it be odd if I were then to claim that the fact that $\mathrm{x}$ is $\mathrm{G}$ gives me a further reason to do the same thing, or to deny that it gives me any reason to do it? And would not that show that what I am taking as my reason is the fact that $\mathrm{x}$ possesses the very property which is determined both by 'being F' and 'being G,' and not the fact that it possesses a property which is determined in any one of these two ways in particular? McDowell's view would not exactly preclude this from happening, but it would entail that I must be wrong about my own reason. But it is hard to see what could lead one to think that one would necessarily be mistaken, except perhaps the (question-begging) conviction that only conceptual contents can be reasons.

It can further be objected that if we were to grant that the fact that experiences can provide reasons suffices to make them conceptually contentful, then it would have to be asked why it is that the fact that actions are done for reasons does not suffice to make them conceptually contentful; what is so special about the antecedent-state role, that it can be fulfilled only by something conceptually contentful? I do not see how McDowell could respond to this, except by denying that actions are within the space of reasons, or by claiming that actions (or more plausibly, whatever it is which can conclude a piece of practical reasoning ${ }^{19}$ ) are conceptually contentful, and neither option seems very attractive.

The foregoing discussion makes it reasonable to conclude that the fact that experiences can provide reasons for beliefs is no good ground for holding that they are conceptually contentful (though nothing in what has been said would conflict with their actually being conceptually contentful). It must now be asked whether a case can be made for the opposite view (apparently embraced by Crane) according to which the fact that experiences are unable to play the consequentstate role is sufficient to make them nonconceptually contentful.

There is no denying that this view has some plausibility, insofar as it is equivalent to the claim that if some state is conceptually contentful (i.e., if its content is conceptual) then it can play the consequentstate role, which looks like a natural thing to say ${ }^{20}$. Moreover, since

${ }^{19}$ One could, for example, claim that only intentions or 'volitions' can play this role. It would certainly be plausible to hold that such states/attitudes must be conceptual; but one who would take this course would also have to deny that anything can strictly provide reasons for actions themselves.

${ }^{20}$ Perhaps the reason why it seems natural, is that every conceptual content must be believable, and every belief is something for which reasons can be given and 
only experiences have been found to be unable to play the consequent-state role, it would give the intuitively acceptable result that only experiences have nonconceptual contents.

But on the other hand, it seems that only the prior conviction that experiences have nonconceptual contents (together with the observation that they are unable to play the consequent-state role) could lead one to accept this claim in the first place, and this makes it look somewhat question-begging. The trouble is that there does not seem to be any necessary connection between the fact that a certain content is conceptual/nonconceptual, and the fact that a state/attitude with this content has or lacks the capacity to play the consequent-state role (or for that matter, the antecedent-state role). I see no reason to deny either that a nonconceptual content could be the content of a state/attitude playing the consequent-state role, or that a conceptual content could be the content of a state/attitude lacking the capacity to play the consequent-state role. And more importantly, I do not see that anything in the nature of conceptual/nonconceptual contents could preclude either possibility. On the contrary, it is likely that if anything can explain why experiences are unable to play the consequent-state role (why there can be no reason for experiencing anything) it is something which has to do with the nature of experiences (or experiencings) themselves, and not with any particular feature of their contents.

The obvious conclusion is that there is no more reason to believe that the content of some state is conceptual only if it can play the consequent-state role than to believe that a state can play the antecedent-state role only if its content is conceptual. This suggests that it is unlikely that the distinction between conceptual and nonconceptual states (or contents) could be explicated in the way contemplated above, by appealing to the fact (even if it is a fact) that both kinds of states cannot be involved in the same kinds of inferences.

\section{Is perceptual experience reason-providing?}

Both Crane and McDowell take it for granted that perceptual experiences do provide reasons for beliefs. Moreover, the cases which they

can thus play the consequent-state role. But of course this shows at most that if the content of some state is conceptual, then some state having this content has the capacity to play the consequent-state role. 
both seem to have primarily in mind are cases where the fact that one perceives (it perceptually appears to one) that $\mathrm{p}$ gives one a reason for believing that $p$, as opposed to cases where the fact that one perceives (it perceptually appears to one that) something gives one a reason for believing something else. McDowell thinks this is possible only if experiences have conceptual contents, and Crane (with many others) disagrees. But there are reasons for doubting that cases of the first kind really are possible, and for thinking that cases of the second kind are possible only if experiences and beliefs both belong to the same family of thetic states/attitudes (which makes it less tempting to maintain that beliefs and experiences cannot have the same kinds of contents).

As far as cases of the first kind are concerned, the problem comes from (i) the fact that one's reason for believing something must be something which is determined by the content of some of one's states/attitudes $^{21}$, and (ii) the plausible assumption that $p$ can never be one's reason for believing that $\mathrm{p}$. In other words, when it perceptually appears to me that $\mathrm{p}$, my reason for believing that $\mathrm{p}$ (if I do believe that $p$ ) cannot be that $p$. It does not follow that one can never have any reason to believe what one experiences, for such a reason may be provided either by some other belief or by the experience of something else. Hence, my experience that $\mathrm{p}$ may give me a reason to believe that q, when I happen to experience (or to have experienced) that $\mathrm{q}$, even if it cannot give me a reason to believe that $\mathrm{p}$. So it is not as if one's reason to believe what one experiences could never be given by any experience. Yet this conflicts with the way in which both Crane and McDowell assume that experiences may provide reasons for beliefs; for when they say that my perceptual experience that $\mathrm{p}$ gives me a reason to believe that $p$, they mean that my reason for believing that $\mathrm{p}$ is that I perceptually experience that $p$ (and not that my

\footnotetext{
${ }^{21}$ That is to say, it must be something which is somehow presented to oneself, and towards which one is directed. Since I have taken the course of identifying contents with modes of presentation and not with what is so presented, I cannot strictly speaking take reasons to be the contents of states/attitudes. In this usage, reasons are the truth-conditions or states of affairs which are determined by mental contents. This is not to deny that the notion of content may also be used in such a way as to refer to these truth-conditions themselves. In other words, I take it that contents as modes-of-presentation, or fregean contents, must be sharply distinguished from contents as states-of-affairs, or russellian contents. Only russellian contents can strictly speaking be reasons.
} 
reason for so believing is that $p$ ). But that I perceptually experience that $p$ is obviously not determined by the content of any perceptual experience of mine, even if it can be one of my reasons only if it is determined by the content of some further state/attitude of mine.

Whether or not this further state/attitude must be thought of as a belief or as a kind of experiential state/attitude, and whether or not it must be conceptually contentful, need not concern us here. For in any case, there will, at some point, be some state/attitude the content of which determines one of my reasons, but such that my being in this state is not among my reasons, because it fails to be determined by the content of any state/attitude of mine. And if this may happen somewhere in the regress, it could as well happen at the beginning. In other words, there is no reason to deny that I may perceptually experience that $\mathrm{p}$ and yet lack any reason to believe that $\mathrm{p}$ (which is not to deny that I may nonetheless be justified in believing that $p$ ), just because I have no relevant attitude towards the fact that I perceptually experience that p. However, even if this forces one to reinterpret Crane's and McDowell's examples, it does nothing to threaten the assumption that perceptual experiences may sometimes provide reasons for beliefs.

Now consider cases of the second kind, i.e., cases where one perceptually experiences that $p$ (and does not otherwise believe it), and one's reason to believe that $q$ is (at least in part) that $p$. The point I want to make now is that this can happen only if perceptual experiences share one important feature of beliefs, namely, that of being thetic states/attitudes. More generally, I contend that the fact that $\mathrm{p}$ cannot be a reason for me to believe anything, unless it is determined by the content of some thetic state of mine ${ }^{22}$, that is to say, unless it is something which I somehow endorse (or to which I implicitly or explicitly assent).

Suppose I know that when Sam is asked to choose among several things, and one of these things is red, he always chooses the red thing.

\footnotetext{
${ }^{22}$ Some authors, such as Dancy (2000), seem to use the word 'reason' in such a way that a fact or true proposition can be a reason for doing something even it is not believe by anyone. Such a view does not necessarily conflict with the one I am recommending, for I am focusing on what it is for someone to have a reason, not on there being reasons for acting in a certain way. Yet it is not clear that Dancy would want to endorse such a distinction, and accept to say that one might have a reason to act in a certain way even when there is no reason to act in that way. The whole matter would require a much more extensive discussion than I can provide here.
} 
Suppose further that I am presented several colored things, exactly one of which looks red to me, and I am asked to predict what will be Sam's choice when he will be presented the same things. If I visually experience that object $\mathrm{A}$ is red, then (part of) my reason for predicting that Sam will choose A could be that A is red. Obviously, my reason (that $\mathrm{A}$ is red) would then have been supplied by my visual experience; but this is not to say that it would necessarily count as my reason in virtue of the fact that it is determined by the content of one of my experiences. Perhaps what happened is that I realized that I visually experienced that $A$ is red, which gave me a reason to believe that $A$ is red, which in turn gave me a reason to believe that Sam will choose A.

Now suppose that A is not in fact red, but looks red because of some lighting trick. If I am completely unaware of this fact, I still have a reason to believe that Sam will choose A. But If I am aware of this, then (ceteris paribus) I have no such reason, even though it still visually appears to me that $A$ is red. Nothing needs to have changed in the content of my experience. What makes the difference, it would seem, is that $A$ 's being red is determined by the content of some thetic state/attitude of mine in the one case, but not in the other. In the one case, it visually appears to me that (or 'as if') A is red and I 'endorse' that A is red, while in the other case it visually appears to me that A is red but I do not 'endorse' that A is red. It would intuitively be wrong to say that there is one case where I perceive that A is red and another where it just appears to me that A is red; for in the sense in which one can perceive that $\mathrm{p}$ only if $\mathrm{p}$, in none of these two cases do I perceive that A is red.

Should we say that the endorsement is part of the experience itself or that it is a further state/attitude which normally accompanies perceptual experiences? Or more accurately, should we hold or deny that 'it perceptually appears to one that p' entails that 'one endorses that p'? In light of what has just been said, only on the first option will it be the case that experiential states/attitudes can provide reasons for beliefs. The price to pay for this is to accept that I am in a completely different kind of state when I know (or just assume) that I am hallucinating and when I do not. Since it seems hard to deny that it visually appears to me that A is red when I endorse that A is red, it will have to be denied that this it what happens when I do not endorse that A is red. 
This is somewhat unnatural, and may tempt one to deny that the endorsement of the content of an experiential state is part of the experiential state itself, and to maintain that my experience remains the same whether or not I know that I am hallucinating. But if this is so, and if I have no reason to believe that Sam will choose A when I know I am hallucinating, while I have some reason to believe this when I do not know it, then what provides me with a reason (when I do have one) cannot be (my being in) this experiential state itself. It must be my endorsement of the content of this experiential state.

Taking this stance would conflict with Crane and McDowell's common assumption, but it would not prevent one from holding that there is a sense in which my reason for believing that Sam will choose A comes from my experience (even if it is not provided by it); for my reason is that A is red, and this would actually be determined by the content of some experiential state of mine. What would make it my reason, however, would not be that I experience that $\mathrm{A}$ is red, but that I endorse it (i.e., that it is the content of some thetic state/attitude of mine). And my reason for endorsing it, if I were to have such a reason, would most probably not be determined by the content of any further experiential state of mine (and certainly not by the content of this very experiential state). On the other hand, whether or not I have a reason for endorsing the content of my visual experience that $\mathrm{A}$ is red (i.e., for having a thetic attitude towards the fact that $\mathrm{A}$ is red), it is likely that part of the cause of my endorsing it (if I do endorse it) would be the fact that I visually experience that $\mathrm{A}$ is red.

We do not really have to choose here between accepting and denying that perceptual experiences are thetic states (involving the endorsement of their content) ${ }^{23}$. For in either case, it will have to be concluded that the 'space of reasons' cannot be wider than the space of thetic states/attitudes. And the issue has no bearing on whether the space of reasons is wider than the 'space of concepts' (or conceptual thoughts). For all that has been said, there is nothing to prevent one's

\footnotetext{
${ }^{23}$ I do however have a preference for the view that perceptual experiences are thetic. For if this is denied, experiences will have to be seen as states which (i) are contentful, and yet (ii) do not play any role at all in the reasonings of those who are in these states. But it is hard to see what could be the point of claiming that there are such states, or how they could acquire any content at all. Hence, I am inclined to think that what is common to the state I am in when I assume I am hallucinating and the state I am in when I assume I am not hallucinating, is just that they have the same content, and not that they are both 'perceptual experiences.'
} 
thetic states/attitudes from having nonconceptual contents; and once this is granted, it does not matter whether one is willing to count such nonconceptual thetic states/attitudes as 'beliefs' or prefers to give them some other name.

If it is denied that perceptual experiences are thetic, then it will have been found that they do not provide reasons for anything; since only thetic states/attitudes can provide reasons ${ }^{24}$, and that the dispute between Crane and McDowell thus rests in part on a mistaken assumption.

But even then, the fact that experiences (so construed) can no more play the antecedent-state role than the consequent-state role would be no ground for thinking either that their contents are conceptual or that they are nonconceptual. What would be significant, is that no reason could then have its source in perceptual experience, unless it was possible for the content of such an experience to be the content of some thetic state/attitude. On this hypothesis, it would thus be possible to conclude that the content of an experience can or cannot be nonconceptual, if it could be shown that the content of a thetic state/attitude can or cannot be nonconceptual. But an argument to this conclusion could hardly rest on the fact that some thetic states/attitudes lack the dual role property, for (in this scenario) there would no longer be any reason to doubt that any thetic state/attitude lacks this property. Hence we would once again be led to the conclusion that one cannot appeal to the distinctive inferential properties of certain states/attitudes in order to claim either that they are or that they are not conceptually contentful ${ }^{25}$.

Daniel Laurier Département de philosophie, Université de Montréal C.P. 6128, Succ. Centre-Ville, Montréal, Qc H3C 3J7 daniel.laurier@umontreal.ca

${ }^{24}$ This may evoke the coherentist dictum according to which only beliefs can justify beliefs. But it must be stressed that one can hold that only thetic states can provide reasons for thetic states and deny that a thetic state is justified only if it rests on some reasons.

${ }^{25}$ Part of this paper has been presented in May 2004, at the Canadian Philosophical Association annual meeting in Winnipeg. I wish to thank Jay Cook for his comments on this occasion. 
References

Alston, William P. 1989. Concepts of Epistemic Justification. In Epistemic Justification. Ithaca: Cornell University Press.

Crane, Tim. 1992. The Nonconceptual Content of Experience. In The Contents of Experience, ed. by Tim Crane. Cambridge: Cambridge University Press.

Dancy, Jonathan. 2000. Practical Reality. Oxford: Oxford University Press.

Humberstone, I. L.1992. Direction of Fit. Mind 101: 59-83.

Laurier, Daniel. Forthcoming. Nonconceptual contents vs Nonconceptual States. Grazer Philosophische Studien.

McDowell, John. 1994. Mind and World. Cambridge (Mass.): Harvard University Press.

McDowell, John. 2002. Responses. In Reading McDowell, ed. by Nicholas H. Smith. London: Routledge.

Peacocke, Christopher. 1992. A Study of Concepts. Cambridge (Mass.): MIT Press.

Stampe, Dennis W. 1987. The Authority of Desire. The Philosophical Review 96: 335-381. 